\title{
Pelatihan Pembuatan Batako Desa Jatimulyo Kecamatan Kauman Kabupaten Tulungagung Lokal
}

\author{
Laily Fatmawati ${ }^{1}$, Lyya Supriono ${ }^{2}$, Dwi Nor Amadi ${ }^{3}$ \\ ${ }^{1}$ Fakultas Teknik, Universitas Merdeka Madiun, Jl. Serayu No.79, Madiun, 63133 \\ E-mail: laily@unmer-madiun.ac.id \\ ${ }^{2}$ Fakultas Teknik, Universitas Merdeka Madiun, Jl. Serayu No.79, Madiun, 63133 \\ E-mail: lyya@unmer-madiun.ac.id \\ ${ }^{3}$ Fakultas Teknik, Universitas Merdeka Madiun, Jl. Serayu No.79, Madiun, 63133 \\ E-mail:dwinor@unmer-madiun.ac.id
}

\begin{abstract}
The majority of the people of Jatimulyo Village are involved in agriculture, to broaden their horizons and hone the creativity of the younger generation to be more developed among them by providing skills training in making concrete blocks which can later be used to prepare business for the procurement sector. Besides being able to reduce the unemployment rate, it can also improve the community's economy. Increasingly, development growth in the construction sector tends to increase so that market opportunities for material marketing, especially concrete blocks, will certainly increase. The results obtained by conducting brick building training are to increase the insight and skills of youth youth in making concrete blocks, as well as to improve the welfare of youth youth and village residents in particular.
\end{abstract}

Keywords —: concrete blocks; socialization; material; tools.

\section{PENDAHULUAN}

\section{A. Latar Belakang}

Desa Jatimulyo terletak di sebelah utara Kecamatan Kauman, dengan jarak tempuh dari ibu kota Kabupaten Tulungagung kurang lebih $6,5 \mathrm{~km}$ kearah barat agak keutara, sekitar kurang dari 12 menit perjalanan. Desa Jatimulyo secara administrasi yaitu terletak pada geografis $8^{\circ} 1^{\prime} 25^{\prime}$ " LS - $8^{\circ} 2^{\prime} 38^{\prime \prime} \mathrm{LS}$ serta $111^{\circ} 52^{\prime} 07^{\prime \prime} \mathrm{BT}-111^{\circ} 53^{\prime} 18^{\prime \prime}$ BT dengan luas keseluruhan $1,48 \mathrm{~km}^{2}$.

Desa Jatimulyo terdiri dari dua Dusun, yaitu Dusun Jabon dan DusunPatikreco yang masing-masing dikepalai seorang Kepala Dusun. Di Dusun Jabon terdapat satu Dukuh tersendiri yaitu Dukuh Baran. Kedua Dusun tersebut terbagi kedalam tujuh Rukun Warga (RW) dan 35 Rukun Tetangga (RT).Dilihat dari tingkat kabupaten, kondisi topografi terbagi menjadi tiga dataran, yaitu dataran tinggi (700 mdpl), dataran sedang(500 - $700 \mathrm{mdpl}$ ), dan dataran rendah (<500 mdpl). Berdasarkan klasifikasi tersebut, Desa Jatimulyo termasuk dalam dataran rendah, yaitu dengan ketinggian rata-rata 163,20 mdpl.

Mayarakat Desa Jatimulyo mayoritas mengeluti bidang pertanian, untuk memperluas wawasan dan mengasah kreatifitas generasi muda agar lebih berkembang diantara dengan memberikan pelatihan ketrampilan pembuatan batako yang nantinya dapat digunakan untuk bekal mebuka usaha disektor pengadaan matrial. Selain dapat menguranngi tingkat pengangguran juga dapat meningkatkan perekonomian masyarakat.

\section{B. Identifikasi dan Perumusan Masalah}

Berdasarkan analisis situasi dilingkungan mitra maka dalam dirumuskan permasalahan antara lain :

1. Pelatihan pembuatan batako sangat potensial untuk dilaksanakan mengingat sumber daya alam dan SDM yang ada dan belum diberdayakan dan terorganisasi

2. Pemuda-pemuda karang taruna yang belum memahami dan belum banyak menciptakan lapangan kerja untuk pembuatan batako

3. Pemuda-pemuda karang taruna yang belum memahami dan menguasai sarana prasarana, teknologi, produksi dan proses produksi serta pemasaran secara terstruktur

\section{Tujuan Pengabdian Kepada Masyarakat}

Tujuan kegiatan ini adalah sebagai berikut:

1. Pelatihan pembuatan batako dapat meningkatkan pengelolaan usaha baik proses produksi maupun pemasaran produk.

2. Peningkatan kesejahteraan pemuda-pemuda karang taruna dan masyarakat pedesaan melalui pelatihan batako ini. 
Website : http://dayamas.unmermadiun.ac.id/index.php/dayamas

\section{Manfaat Kegiatan}

Manfaat yang diharapkan dari kegiatan pengabdian pada masyarakat ini adalah :

1. Memberikan keterampilan kepada pemuda-pemuda karang taruna dalam membuat batako untuk meningkatkan kesejahteraan pemuda-pemuda karang taruna dan warga desa pada khususnya.

2. Sebagai forum untuk bersosialisasi tentang cara membuat batako, menambah wawasan untuk pemuda-pemuda karang taruna dan warga desa khususnya.

\section{METODE PELAKSANAAN}

Berdasarkan kesepakatan dengan pemuda-pemuda karang taruna mitra untuk menyelesaikan permasalahan yang ada maka pengusul proposal menggunakan metode pendekatan dengan kegiatan pelatihan dalam pengabdian kepada masyarakat ini. Pelatihan akan dilaksanakan dengan dua tahap yaitu teori dan praktek membuat batako di lapangan. Kerjasama pemuda-pemuda karang taruna mitra dan peran aktifnya dalam kegiatan pelatihan sangat diharapkan demi keberhasilan pelatihan ini. Dalam pelatihan ini akan didukung oleh beberapa narasumber yang akan menyampaikan materinya. Pada kegiatan pertama peserta pelatihan akan menerima materi tentang cara membuat batako. Kemudian pada tahap kedua peserta akan melihat dan langsung praktek membuat batako tersebut.

\section{III.HASIL DAN PEMBAHASAN}

\section{Materi Pengabdian}

\section{A. Pengertian Batako}

Batako berasal dari campuran semen, agregat, dan air dengan atau tanpa bahan tambahan. Batako yang dihasilkan oleh industri kecil pada umumnya adalah batako padat. Batako tersebut dilihat secara langsung menunjukkan kualitas yang cukup baik dengan permukaan yang mulus. Dari hasil peninjauan di lapangan menunjukkan adanya perbedaan hasil yang dicapai antara industri kecil dan industri rumah tangga dalam hal jumlah batako yang dihasilkan dalam satu zak semen. Batako yang dihasilkan oleh industri kecil bervariasi antara 90-120 buah sedangkan pada industri rumah tangga bervariasi antara 60-80 buah batako. Dengan adanya perbedaan jumlah batako yang dihasilkan dalam satu zak semen akan memberikan perbedaan kuat tekan yang mana jumlah batako yang dihasilkan lebih banyak memiliki nilai kuat tekan yang lebih kecil dibandingkan jumlah batako yang dihasilkan lebih sedikit.

Batako mempunyai sifat-sifat panas dan ketebalan total yang lebih baik dari pada beton padat. Jika dibandingkan dengan batu bata, batako memiliki keuntungan tertentu seperti, beratnya hanya $1 / 3$ dari batu bata untuk jumlah yang sama. Batako dapat disusun 4 kali lebih cepat dan cukup kuat untuk semua penggunaan yang biasanya menggunakan batu bata. Dinding yang dibuat dari batako mempunyai keunggulan dalam hal meredam panas dan suara. Semakin banyak produksi beton semakin ramah lingkungan dari pada produksi bata tanah liat karena tidak harus dibakar. Batako Dilihat dari segi pembuatannya batako dibagi menjadi tiga:

\section{Batako Trass Atau Putih.}

Bahan utama yang di pakai adalah kapur, trass kemudian di campur dengan air. karena itu ada yang menamakan batako jenis ini dengan sebutan batu cetak kapur trass. sedangkan trass adalah: salah satu jenis tanah yang asalnya dari batu gunung berapi yang mengalami pelapukan.

\section{Batako Semen/Press.}

Batako press dibuat dari campuran semen dan pasir atau abu batu. Ada yang dibuat secara manual (menggunakan tangan) dan ada juga yang menggunakan mesin. Perbedaanya dapat dilihat pada kepadatan permukaan batakonya. Umumnya memliki panjang $36-40 \mathrm{~cm}$ dan tinggi $18-20 \mathrm{~cm}$. terdapat lubang di bagian sisinnya untuk pengikat ketika di pasang. lubang tersebut jumlahnya tiga atau dua.

\section{Bata Ringan/Hebel.}

Bata ringan dibuat dari bahan batu pasir kuarsa, kapur, semen dan bahan lain yang dikategorikan sebagai bahan-bahan untuk beton ringan.

Batako diklasifikasikan menjadi dua golongan yaitu batako normal dan batako ringan. Batako normal tergolong batako yang memiliki densitas sekitar 2200-2400 kg/m3 dan kekuatannya tergantung komposisi campuran beton (mix design). Sedangkan untuk beton ringan adalah suatu batako yang memiliki densitas $<1800 \mathrm{~kg} / \mathrm{m}^{3}$, begitu juga kekuatannya biasanya disesuaikan pada penggunaan dan pencampuran bahan bakunya (mix design). Jenis batako ringan ada dua golongan yaotu : batako ringan berpori (aerated concrete) dan batako ringan non aerated. (Wisnu wijanarko. 2008)

Batako ringan berpori adalah beton yang dibuat sehingga strukturnya banyak terdapat pori-pori, beton semacam ini diproduksi dengan bahan batu dari campuran semen, pasir, gypsum, $\mathrm{CaCO} 3$ dan katalis aluminium. Dengan adanya katalis $\mathrm{Al}$ selama menjadi reaksi hidradasi semen akan menimbulkan panas sehingga timbul gelembung-gelembung yang menghasilkan gas yang menghasilkan pori-pori yang membuat batako semakin ringan. Berbeda dengan batako non aerated, pada beton ini 
Website : http://dayamas.unmermadiun.ac.id/index.php/dayamas

akan menjadi ringan dalam pembuatannya ditambahkan agregat ringan. Banyak kemungkinan agregat ringan yang digunakan antara lain batu apung (pumice), perlit, serat sintesis, slag baja dan lain-lain. Pembuatan batako ringan berpori tentunya jauh lebih mahal karena menggunakan bahan-bahan kimia tambahan dan mekanisme pengontrolan reaksi cukup sulit.

\section{B. Alat dan Bahan Pembuatan Batako}

Bahan-bahan yang diperlukan :

\section{Semen}

Semen adalah bahan yang mempunyai sifat adhesif dan sifat kohesif yang digunakan sebagai bahan pengikat (bonding material) yang dipakai bersama dengan batu kerikil, pasir dan air. Portland semen merupakan bahan utama atau komponen beton terpenting yang berfungsi sebagai bahan pengikat anorganik dengan bantuan air dan mengeras secara hidrolik.

Semen portland yang digunakan sebagai bahan struktur harus mempunyai kualitas yang sesuai dengan ketepatan agar berfungsi secara efektif. Pemeriksaan dilakukan terhadap yang masih berbentuk kering, pasta semen yang masih keras dan beton yang dibuat darinya.

Sifat kimia yang perlu mendapat perhatian adalah kesegaran semen itu sendiri. Semakin sedikit kehilangan berat berarti semakin sedikit kesegaran semen. Dalam keadaan normal kehilangan berat sebesar $2 \%$ dan maksimum kehilangan yang diijinkan 3\%. Kehilangan berat terjadi karena adanya kelembaban dan karbondioksida dalam bentuk kapur bebas atau magnesium yang menguap.

2. Pasir

Pasir merupakan bahan pengisi yang digunakan dengan semen untuk membuat adukan. Selain itu juga pasir berpengaruh terhadap sifat tahan susut, keretakan dan kekerasan pada batako atau produk bahan bangunan campuran semen lainnya.Pada pembuatan batako ringan ini digunakan pasir yang lolos ayakan kurang dari $5 \mathrm{~mm}$ (ASTM E 11-70) dan harus bermutu baik yaitu pasir yang bebas dari lumpur, tanah liat, zat organik, garam florida dan garam sulfat. Selain itu juga pasir harus bersifat keras, kekal dan mempunyai susunan butir (gradasi) yang baik.

Menurut Persyaratan Bangunan Indonesia agregat halus sebagai campuran untuk pembuatan beton bertulang harus memenuhi syarat-syarat sebagai berikut:

a. Pasir harus terdiri dari butir-butir kasar, tajam dan keras.

b. Pasir harus mempunyai kekerasan yang sama.

c. Agregat halus tidak boleh mengandung lumpur lebih dari 5\%, apabila lebih dari 5\% maka agregat tersebut harus dicuci dulu sebelum digunakan. Adapun yang dimaksud lumpur adalah bagian butir yang melewati ayakan 0,063 $\mathrm{mm}$.

d. Pasir harus tidak boleh mengandung bahan-bahan organik terlalu banyak.

e. Pasir harus tidak mudah terpengaruh oleh perubahan cuaca.

f. Pasir laut tidak boleh digunakan sebagai agregat untuk beton.(Wijanarko, W.2008)

3. Air

Air yang dimaksud disini adalah air yang digunakan sebagai campuran bahan bangunan, harus berupa air bersih dan tidak mengandung bahan-bahan yang dapat menurunkan kualitas batako. Menurut PBI 1971 persyaratan dari air yang digunakan sebagai campuran bahan bangunan adalah sebagai berikut:

a. Air untuk pembuatan dan perawatan beton tidak boleh mengandung minyak, asam alkali, garam-garam, bahanbahan organik atau bahan lain yang dapat merusak dari pada beton.

b. Apabila dipandang perlu maka contoh air dapat dibawa ke Laboratorium Penyelidikan Bahan untuk mendapatkan pengujian sebagaimana yang dipersyaratkan.

c. Jumlah air yang digunakan adukan beton dapat ditentukan dengan ukuran berat dan harus dilakukan setepattepatnya.

d. Air yang digunakan untuk proses pembuatan beton yang paling baik adalah air bersih yang memenuhi syarat air minum. Jika dipergunakan air yang tidak baik maka kekuatan beton akan berkurang. Air yang digunakan dalam proses pembuatan beton jika terlalu sedikit maka akan menyebabkan beton akan sulit dikerjakan, tetapi jika air yang digunakan terlalu banyak maka kekuatan beton akan berkurang dan terjadi penyusutan setelah beton mengeras.(Wijanarko, W. 2008) 
Perlatan yang diperlukan :

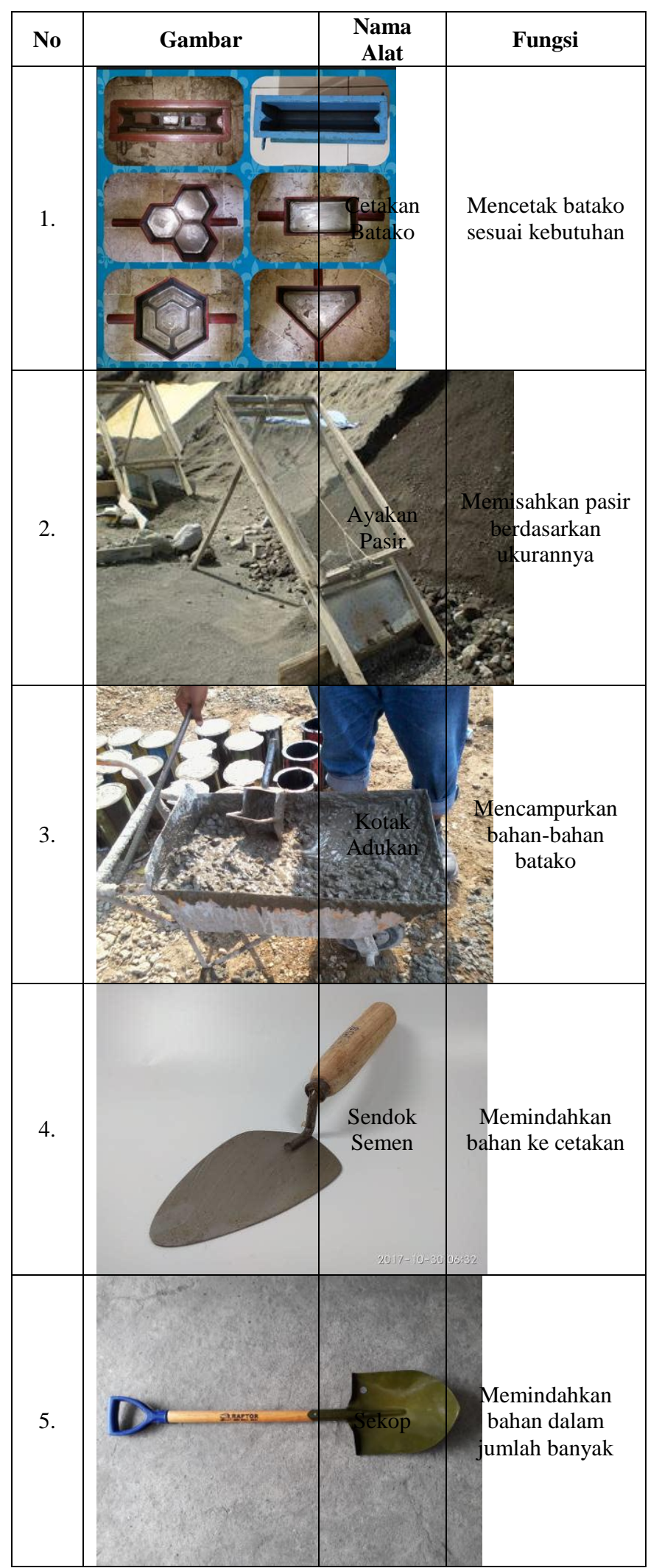


Website : http://dayamas.unmermadiun.ac.id/index.php/dayamas

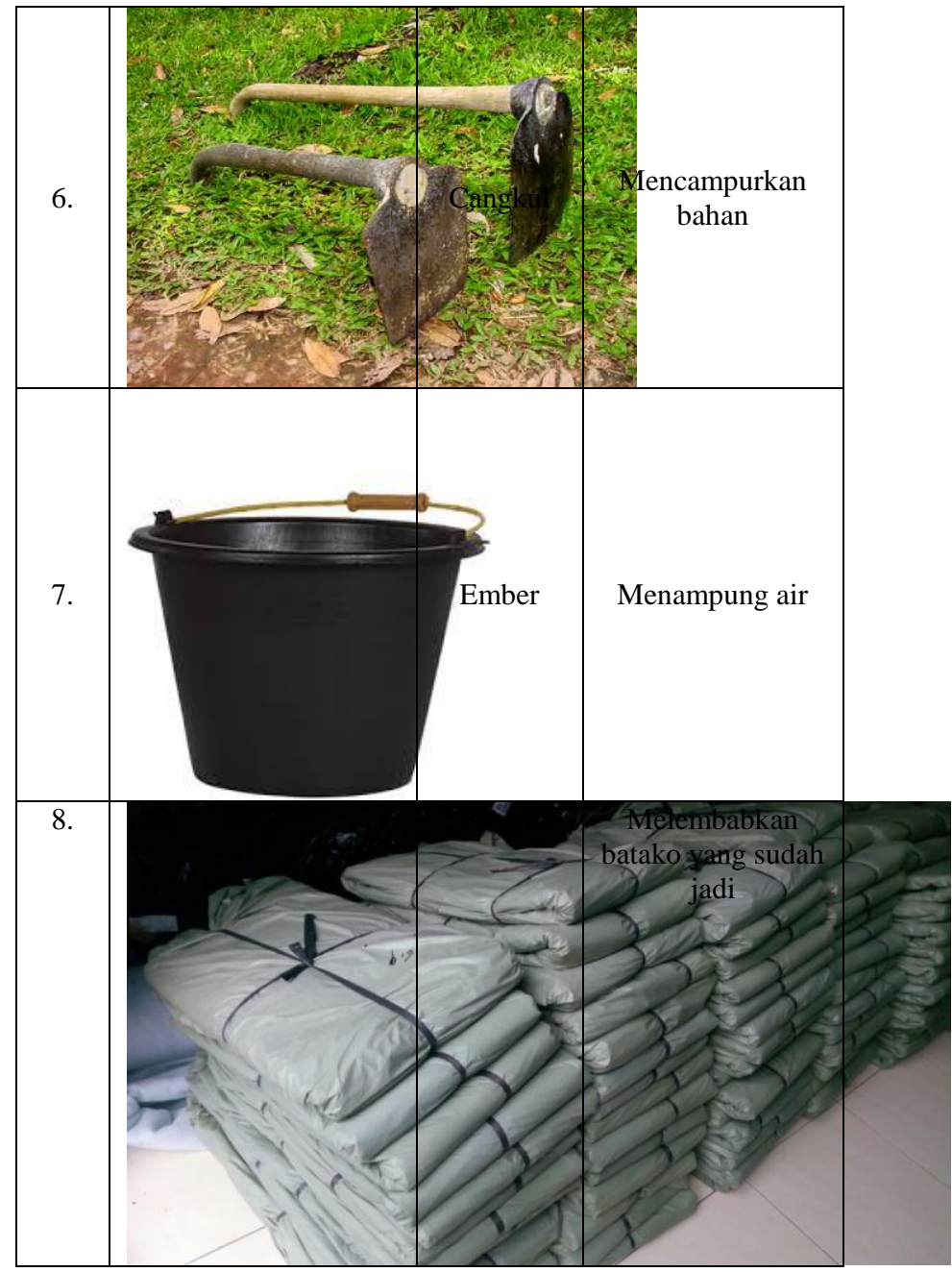

\section{Proses Pembuatan Batako}

1. Tahap Persiapan

Siapkan perkakas, peralatan dan bahan. Ayak pasir pertama dengan ayakan pasir $1 \mathrm{~cm} 2$ untuk memisahkan batu-batu yang besar. Lalu ayak lagi dengan ayakan yang lebih kecil untuk mendapatkan pasir halus. Pasir harus bersih dari kotoran, sampah dan lumpur.

\section{Tahap Pencampuran/Pengadukan}

a. Taburkan sejumlah pasir yang telah diukur setebal $10 \mathrm{~cm}$ di kotak adukan.

b. Tuang semen di atas pasir dan aduk keduanya secara bersama-sama sampai warna keduanya tercampur.

c. Bentuk adukan menjadi gundukan, dan buat lubang seperti cekungan di tengah.

d. Siram dengan sedikit air secara perlahan dan aduk sampai terbentuk pasta yang merata.

e. Jika menggunakan kerikil, sekarang tambahkan dalam takaran yang sesuai kerikil dan aduk hingga setiap kerikil terlapisi secara merata.

f. Periksa adukan: ambil segenggam penuh adukan dan bentuk seperti bola kecil. Jika bola tersebut tidak retak, dan tangan sedikit basah, adukan siap untuk dicetak.

g. Untuk perbandingan adukannya digunakan 1 bagian semen bermutu baik +2 bagian pasir sungai yang bersih +3 bagian kerikil + Air secukupnya.

\section{Tahap Persiapan Cetakan}

a. Masukkan adukan beton kedalam ember.Tempatkan bagian bawah cetakan ke tempat yang benar (di bawah atap atau tempat teduh lainnya)

b. Beri oli dibawah cetakan.

c. Tuang adukan beton kedalam cetakan.

d. Letakkan alat tekan cetakan di atas bagian bawah cetakan. 
Website : http://dayamas.unmermadiun.ac.id/index.php/dayamas

e. Tekan alat tekan lurus ke bawah hingga "bagian kakinya"menyentuh lantai pada ke dua sisi.

f. Injak dengan kaki ke atas "kaki" alat tekan cetakan, tekan cetakan, ambil pegangan bagian bawah cetakan, perlahan - lahan angkat bagian atas cetakan.

g. Letakkan bagian bawah cetakan ke tanah secara perlahan.

h. Keluarkan peralatan tekan dari bagian bawah cetakan. pisahkan ke samping.

i. Perlahan-lahan angkat bagian bawah cetakan ke atas, dan tempatkan di samping batako yang baru jadi.

j. Biarkan batako yang baru selama 1 hari, jangan kena sinar matahari langsung.

k. Setelah 1 hari, batako ditumpuk dan dilakukan curing selama seminggu.

1. Bersihkan cetakan dari debu dan beri minyak lagi di cetakan dan batako berikutnya siap dicetak.

\section{Kriteria Batako yang Baik}

Adapun kriteria batako yang baik diantaranya masing-masing permukaanya rata dan saling tegak lurus serta mempunyai kuat tekan yang tinggi. Persyaratan batako menurut PUBI 1982 pasal 6 antara lain adalah " permukaan batako harus mulus, berumur minimal satu bulan, pada waktu pemasangan harus sudah kering, berukuran panjang $400 \mathrm{~mm}$, lebar 200 mm dan tebal 100-200 mm, kadar air 25-35\% dari berat, dengan kuat tekan antara 2-7 N/mm2".

Sebelum dipergunakan dalam bangunan, minimal batako harus sudah berumur satu bulan dari proses pembuatannya, kadar air pada waktu pemasangan tidak lebih dari $15 \%$. Agar didapat mutu batako yang memenuhi syarat SI.

\section{E. Faktor Pengaruh Mutu Batako}

Faktor yang mempengaruhi mutu batako tergantung pada :

1. Faktor air semen

2. Umur batako

3. Kepadatan batako

4. Bentuk dan struktur batuan

5. Ukuran agregat, dan lain-lain.

\section{F. Pelatihan Pembuatan Batako}

Setelah dilakukan sosialisasi materi pembuatan batako serta mempersiapkan alat dan bahan yang diperlukan langkah selanjutnya adalah praktek pembuatan batako.

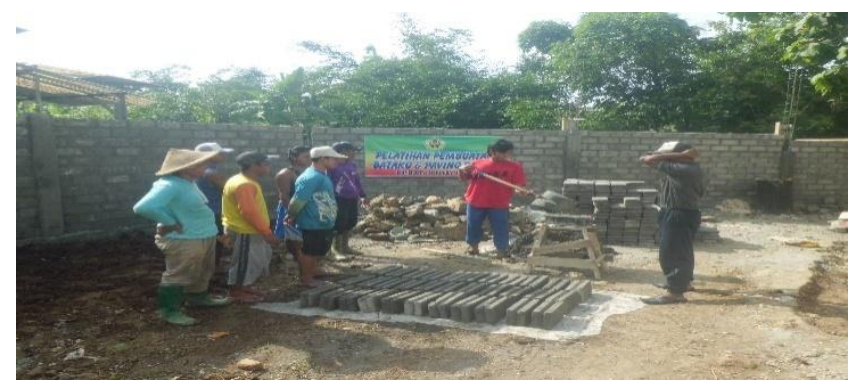

Gambar 1. Pencampuran matrial dan pencentakan

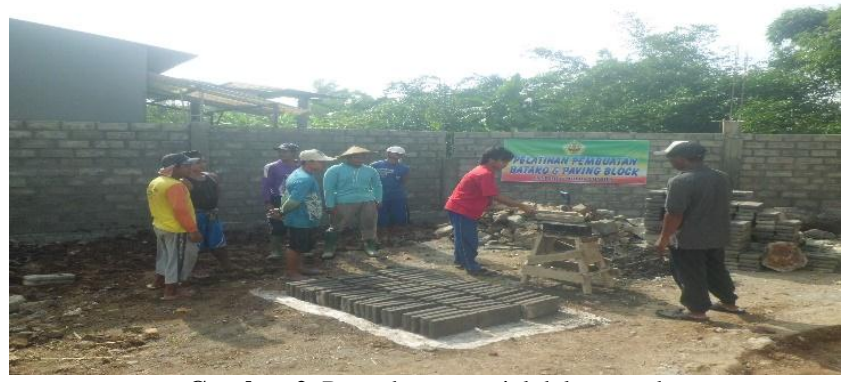

Gambar 2. Pemadatan matrial dalam cetakan 


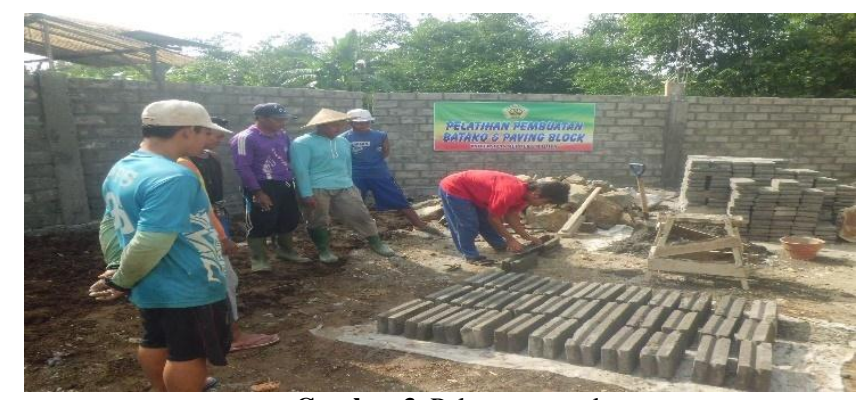

Gambar 3. Pelepasan cetakan

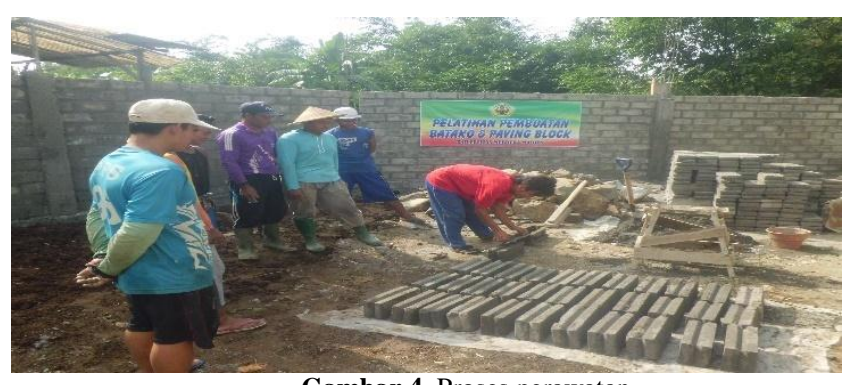

Gambar 4. Proses perawatan

\section{G. Pelaksanaan Kegiatan}

Kegiatan pengabdian ini dilaksanakan pada:

Tanggal : 29 September 2018

Waktu : jam $8.00 \mathrm{~s} / \mathrm{d} 16.00 \mathrm{WIB}$

Kegiatan :

1. Sosialisasi bahan bahan dan peralatan yang dibutuhkan

2. Sosialisasi cara proses pembuatan batako

3. Persiapan bahan dan peralatan pembuatan batako

4. Praktek Pembuatan batako

\section{H. Hasil Kegiatan}

Adapun hasil yang diperoleh dengan melakukan pelatihan Batako adalah sebagai berikut:

1. Meningkatkan keterampilan pemuda-pemuda karang taruna dalam membuat batako untuk meningkatkan kesejahteraan pemuda-pemuda karang taruna dan warga desa pada khususnya.

2. Meningkatkan wawasan untuk pemuda-pemuda karang taruna dan warga desa khususnya.

\section{IV.KESIMPULAN}

Dari penjelasan diatas maka disimpulkan bahwa telah dilaksanakan pelatihan pembuatan batako di Desa Jatimulyo Kecamatan Kauman Kabupaten Tulungagung dengan cara praktek langsung dilapangan.

\section{UCAPAN TERIMAKASIH}

Terima Kasih Kepada Lembaga Penelitian dan Pengabdian Kepada Masyarakat Universitas Merdeka Madiun.

\section{VI.DAFTAR PUSTAKA}

Departemen Pekerjaan Umum Direktorat Cipta Karya,1982, ”Persyaratan Umum Bahan Bangunan di Indonesia”, Yayasan lembaga Pendidikan masalah Bangunan, Bandung.

Merisuranti, 2017, Makalah pembuatan batako, https://merisuranti28.blogspot.com,tanggal akses 2 Agustus 2018.

Tri Mulyono. 2005. Teknologi Beton, Penerbit Andi.Yogy Yogyakarta. 